\title{
Assessment of Knowledge, Attitude and Practice Regarding Biomedical Waste Management among Health Care Personnel in Jawahar Lal Nehru Medical College and Hospital, Ajmer (Rajasthan)
}

\author{
Mohit Sharma $^{1 *}$, Mahima Sharma ${ }^{2}$, Priyanka Kapoor ${ }^{3}$, Suryakant Verma ${ }^{4}$, Rekha Maheshwari ${ }^{5}$, H.P. Gupta ${ }^{6}$ \\ ${ }^{1 *}$ Assistant Professor, Department of Cardio-Vascular and thoracic surgery, \\ ${ }^{4}$ Senior Resident, ${ }^{5}$ Professor and Head, ${ }^{6}$ Associate Professor, Department of General Surgery, \\ J.L.N. Medical College, Ajmer, Rajasthan, India. \\ 2Senior Demonstrator, Department of Physiology, R.U.H.S. Medical College, Jaipur, Rajasthan, India. \\ ${ }^{3}$ Senior Resident, Department of Community Medicine, S.M.S. Medical College, Jaipur, Rajasthan, India.
}

\begin{abstract}
Background: Lack of proper knowledge and faulty practices in biomedical waste management is common in developing countries like India. This study was conducted in the department of surgery of a tertiary level hospital attached with medical college. The purpose of the study was to evaluate lacunae in disposal of hospital generated wastes and recommend steps to rectify the prevalent scenario.

Material and Methods: An observational cross sectional study was undertaken in the department of surgery, J.L.N. Medical College, Ajmer (Rajasthan) in the month of January 2016, with a study group of 123 health care professionals comprising of doctors, nursing staff and class 4 workers. A semi structured questionnaire was used to assess knowledge, attitude and practices regarding Biomedical Waste Management among the study group. The data was analyzed using proportion and percentages.
\end{abstract}

Results: The data showed that knowledge regarding hazardous nature of biomedical waste, duration of waste storage and utility of plastic bags were less than satisfactory levels. Only $42 \%$ of doctors and $31 \%$ of nursing staff had undergone BMW (Bio-Medical Waste) management training. They were however, willing to be part of BMW management plan and majority of the group agreed on the need to conduct CME programs to upgrade knowledge. Faulty practices were noted in disposal of pharmaceutical waste, sharps and general

\section{INTRODUCTION}

The term "biomedical waste (BMW)" is defined as "any waste that is generated during diagnosis, treatment, immunization of human beings or animals, in the research activities pertaining to their production or testing.1,2 Biomedical waste management has recently emerged as an issue of major concern not only to hospitals, nursing home authorities and health care centers but also to the surrounding environment.,3 Advances in medical facilities and the introduction of more sophisticated instruments has increased the waste generation per patient in health care units worldwide. ${ }^{5}$ It is estimated that $20-25 \%$ of the healthcare waste. Majority claimed that they use the personal protective equipment (PPE) i.e. gloves etc.

Conclusion: Inference drawn from the data shows an enterprising attitude of health care workers towards BMW management, but prevalence of wrong practices mostly stemming from lack of knowledge. This study shows that there is a regular need for CME (Continuing Medical Education) in the department of surgery, for improving the knowledge of health care personnel.

Keywords: Biomedical Waste, Health Personnel, KAP.

\section{${ }^{*}$ Correspondence to:}

Dr Mohit Sharma,

Assistant Professor,

Department of Cardio-Vascular and thoracic surgery, J.L.N. Medical College, Ajmer, Rajasthan, India.

\section{Article History:}

Received: 16-06-2016, Revised: 19-06-2016, Accepted: 28-07-2016

\begin{tabular}{|l|c|}
\hline \multicolumn{2}{|c|}{ Access this article online } \\
\hline $\begin{array}{l}\text { Website: } \\
\text { www.ijmrp.com }\end{array}$ & Quick Response code \\
\hline DOI: & \\
10.21276/ijmrp.2016.2.4.037 & \\
\hline
\end{tabular}

waste generated is hazardous and causes serious health related problems. ${ }^{6}$ The waste thus generated in the hospital has significant health impact not only on the healthcare workers but also on the general public. Inadequate and inappropriate handling of health care wastes has serious public health issues and significant influences on the environment. BMW Management is currently a burning issue due to the aforementioned reasons. India generates around three million tons of biomedical waste each year and its generation is expected to grow at a rate of eight percent annually. 
The absence of proper waste management, lack of awareness about the health hazards from BM waste, insufficient financial and human resources and poor control of waste disposal are the most critical problems. Although there is increased global awareness among health care professionals about hazards management techniques, the level of awareness in India has been found to be extremely inadequate. ${ }^{7}$

Hence this study was undertaken with the objective to assess the knowledge regarding the BMW, to identify the gaps in the practice of effective BMW management by the healthcare workers and to put into practice essential protocols for training of HCWs in the field of BMW management.

\section{MATERIAL AND METHODS}

This is an observational, descriptive; cross sectional hospital based study. The hospital is an 1000 bedded tertiary health care centre associated with medical college, located in Ajmer, Rajasthan. The healthcare workers included in the study have been divided into three sub groups; doctors, nursing staff and class 4 employees. The study sample includes 28 doctors, 80 nursing staff and 15 class 4 workers.

The study was in the form of a pre designed, self-testing questionnaire. The questionnaire was divided into 3 parts; each pertaining to knowledge, attitude and practice. The questions included in each part were developed by the authors after going through articles and studies of a similar context.

The questionnaire was delivered in interview form to the class 4 workers, in simple language that they could comprehend. Confidentiality regarding the identity of the HCW and their responses were maintained. The percentage of correct and incorrect answers for each questions from the participants were obtained and used to interpret the extent of awareness.

Table 1: Displaying proportion of correct responses regarding knowledge about bio medical waste management

\begin{tabular}{llccc}
\hline S.No & Questions regarding BMW knowledge & $\begin{array}{c}\text { Doctors } \\
(\mathbf{n}-\mathbf{2 8})\end{array}$ & $\begin{array}{c}\text { Nursing staff } \\
(\mathbf{n}-\mathbf{8 0})\end{array}$ & $\begin{array}{c}\text { Class } 4 \\
(\mathbf{n}-15)\end{array}$ \\
\hline $\mathbf{1}$ & Hazardous nature of bio- medical waste & $15(53.57 \%)$ & $10(12.5 \%)$ & $2(13.33 \%)$ \\
$\mathbf{2}$ & Awareness of BMW rules & $24(85.71 \%)$ & $77(97.5 \%)$ & $8(53.33 \%)$ \\
$\mathbf{3}$ & Utility of plastic bags & $21(75 \%)$ & $63(78.75 \%)$ & $6(40 \%)$ \\
$\mathbf{4}$ & Bio medical waste categories & $27(96.4 \%)$ & $25(31.25 \%)$ & $1(6.6 \%)$ \\
$\mathbf{5}$ & Disease transmitted by bio medical waste & $26(92.40 \%)$ & $75(93.75 \%)$ & $12(80 \%)$ \\
$\mathbf{6}$ & Duration of storage of bio-medical waste & $28(100 \%)$ & $25(31.75 \%)$ & $10(66 \%)$ \\
$\mathbf{7}$ & Identification of bio-hazard symbol & $27(96.4 \%)$ & $77(96.25 \%)$ & $7(46.66 \%)$ \\
$\mathbf{8}$ & Existence of a plan for BMW management & $26(92.4 \%)$ & $42(52.5 \%)$ & $8(53.33 \%)$ \\
$\mathbf{9}$ & Separate color coding of wastes & $27(96.4 \%)$ & $65(81.25 \%)$ & $12(80 \%)$ \\
$\mathbf{1 0}$ & On receiving BMW management training & $12(42.83 \%)$ & $25(31.25 \%)$ & $4(23.33 \%)$ \\
\hline
\end{tabular}

Table 2: Displaying proportion of correct responses regarding attitude about bio-medical waste management

\begin{tabular}{llccc}
\hline S.No & Questions regarding attitude to BMW management & $\begin{array}{c}\text { Doctors } \\
(\mathbf{n}-28)\end{array}$ & $\begin{array}{c}\text { Nursing staff } \\
(\mathbf{n}-80)\end{array}$ & $\begin{array}{c}\text { Class 4 } \\
(\mathbf{n}-15)\end{array}$ \\
\hline $\mathbf{1}$ & Segregation of wastes into categories & $28(100 \%)$ & $80(100 \%$ & $14(93.33 \%)$ \\
$\mathbf{2}$ & Use of PPE (personal protective equipment ) & $28(100 \%)$ & $74(92.5 \%)$ & $15(100 \%)$ \\
$\mathbf{3}$ & Co-operation to a waste management team & $28(100 \%)$ & $78(97.5 \%)$ & $15(100 \%)$ \\
$\mathbf{4}$ & Responsibility towards waste management & $28(100 \%)$ & $77(96.25 \%)$ & $15(100 \%)$ \\
$\mathbf{5}$ & CME to upgrade knowledge towards BMW & $27(96.40 \%)$ & $73(91.25 \%)$ & $13(86.66 \%)$ \\
$\mathbf{6}$ & Obedience to colour coding & $26(92.40 \%)$ & $70(87.5 \%)$ & $14(93.33 \%)$ \\
$\mathbf{7}$ & Biomedical waste management as an issue & $26(92.40 \%)$ & $79(98.75 \%)$ & $15(100 \%)$ \\
\hline
\end{tabular}

Table 3: Displaying proportion of correct responses regarding practices related to biomedical waste management

\begin{tabular}{llccc}
\hline S.No & $\begin{array}{l}\text { Questions regarding practices related to } \\
\text { biomedical waste management }\end{array}$ & $\begin{array}{c}\text { Doctors } \\
(\mathbf{n}-\mathbf{2 8})\end{array}$ & $\begin{array}{c}\text { Nursing staff } \\
(\mathbf{n}-\mathbf{8 0})\end{array}$ & $\begin{array}{c}\text { Class 4 } \\
(\mathbf{n}-15)\end{array}$ \\
\hline $\mathbf{1}$ & Disposal of cotton, gauze and blood soaked items & $27(96.40 \%)$ & $75(93.75 \%)$ & $2(13.33 \%)$ \\
$\mathbf{2}$ & Disposal of pharmaceutical wastes & $25(89.28 \%)$ & $51(63.75 \%)$ & $10(66.67 \%)$ \\
$\mathbf{3}$ & Disposal of waste sharps & $26(92.83 \%)$ & $70(87.5 \%)$ & $12(80 \%)$ \\
$\mathbf{4}$ & Disposal of rubber materials & $25(89.28 \%)$ & $66(82.5 \%)$ & $14(93.33 \%)$ \\
$\mathbf{5}$ & Disposal of general waste & $27(96.40 \%)$ & $71(88.75 \%)$ & $12(80 \%)$ \\
$\mathbf{6}$ & Disposal of used needles & $23(82.14 \%)$ & $69(86.25 \%)$ & $11(73.33 \%)$ \\
$\mathbf{7}$ & Use of personal protective equipment & $26(92.83 \%)$ & $74(92.5 \%)$ & $13(86.67 \%)$ \\
\hline
\end{tabular}




\section{OBSERVATIONS AND RESULTS}

The study was conducted in the department of surgery among 123 health personnel in the month of January 2016 at Jawahar Lal Nehru Medical College and associate group of hospitals, Ajmer (Rajasthan). They were tested against a semi-structured questionnaire and the data was analyzed using percentage and proportion of correct responses. The observation following analysis of the submitted questionnaires are given in the following tables.

These observations shows that knowledge regarding the hazardous nature of BMW is much lower than expected standards especially amongst nursing staff and class 4 workers $(12.5 \%$ and $13.33 \%$ respectively), whereas awareness amongst doctors was lower than expectorations (53.33\%). The knowledge regarding the correct duration of storage of BMWs was poor amongst both, nursing staff $(31.75 \%)$ and class $4(66 \%)$, however their knowledge about BMW as a disease source was greater $(93.75 \%$ in nursing staff; $80 \%$ in class 4). Disappointingly only $42.83 \%$ of doctors and $31.25 \%$ of nursing staff had received BMW management training. Attitude amongst participants of the study regarding BMW management was encouraging especially in terms of realizing their responsibility towards waste management and volunteering to be a part of a waste management team (greater than $90 \%$ in all 3 groups).

Also awareness regarding segregation of wastes into categories and adherence to color coding rules was high especially in class 4 workers (93.33\%). All groups stressed on use of personal protective equipments (PPE). Majority of doctors (96.40\%) and nurses $(91.25 \%)$ agreed on continuing medical education (CME) programs being held to upgrade their knowledge regarding BMW management.

The review of practices regarding BMW Management revealed that knowledge about disposal of blood soaked items, pharmaceutical wastes and used needles was low especially amongst class 4 workers $(13.33 \%, 66.67 \%$ and $73.33 \%$ respectively). All 3 groups claimed universal use of PPE $(92.83 \%$, $92.5 \% ; 86.67 \%$ amongst doctors, nursing staff and class 4 respectively).

\section{DISCUSSION}

This study revealed that majority of the respondents had a fairly satisfactory knowledge about bio medical waste management. However, some lacunas were identified and few areas where improvisations were required. Only $42.8 \%$ of doctors and $31.25 \%$ of nurses had undergone BMW management training, so there is need for regular CME (continuous medical education) in the department of surgery. The knowledge regarding hazardous nature of waste and utility of plastic bags continue to be areas of concern as reflected in previous studies. ${ }^{8-11}$ It was discovered that doctors had higher level of awareness as compared to nursing staff and class 4 workers, in accordance with previous studies. ${ }^{12}$ Overall attitude of respondents regarding biomedical waste management was more promising than those revealed by studies in other developing countries namely Iran, Bangladesh and Pakistan. ${ }^{13-15}$ A majority of respondents wanted to be a part of an waste management team.

A commendable section of the respondents especially doctors and nursing staff displayed good knowledge of color coding and claimed strict obedience to it, comparable to studies in Bijapur,
Karnataka ${ }^{16}$ and also to a report submitted by Rao et al. ${ }^{17}$ Most of the nursing and class 4 staff demonstrated use of personal protection equipment (PPE) in contrast to studies done in Dakar, Senegal. ${ }^{18}$ Awareness regarding disposal of used needles among nursing and class 4 staff were higher than those in Karimnagar, Andhra Pradesh ${ }^{19}$, but still below satisfactory levels.

\section{CONCLUSION}

It is clear from this study that most of the participants have the right attitude regarding biomedical waste management but faulty practices that is a direct result of lack of knowledge regarding BMW management. This study recommends that continuous medical education (CME) programs and re-orientation programs should be held at regular intervals.

Protocols depicting correct methods of handling infectious and non-infectious waste should be displayed across all nursing stations. The paramedic staff should be provided with safer equipment for personal protection and waste disposal.

\section{REFERENCES}

1. Government of India, Ministry of Environment and Forests. BioMedical Waste (Management and handling) Rules. Gazette of India. 1998 (27 Jul). (Accessed on 31 January 2016)

Available at: http://envfor.nic.in/legis/hsm/biomed.html.

2. Government of India, Ministry of Health and Family Welfare (MoHFW). National Guidelines on Hospital Waste Management Based upon the bio- Medical Waste (Management and Handling) Rules, 1998. New Delhi: MoHFW; 2002. Available from: http://www.vpci.org.in/circular/810_bio\%20waste.pdf

(Accessed on 31 Jan 2016)

3. Mandal SK, Dutta J. Integrated bio-medical waste management plan for Patna city, Institute of Town Planners, India Journal, 2009, 6(2):1-25.

4. Alagoz AZ, Kocasoy G. Improvement and modification of the routing system for the health- care waste collection and transportation in Istanbul. Waste Management, 2008, 28:14611471.

5. Radha KV, Kalaivani K, Lavanya R. A case study of biomedical waste management in hospitals. Global Journal of Health Science, 2009, 1:82-88.

6. Safe management of waste from health care activities. WHO, Geneva; 1999. (Accessed at 31 January 2016) Available at: http://apps.who.int/iris/bitstream/10665/42175/1/9241545259.pdf

7. Pandit NB, Mehta HK, Kartha GP, Choudhary SK. Management of bio-medical waste; Awareness and practices in a district of Gujarat. Indian J Public Health. 2005 Oct-Dec; 49(4):245-7.

8. Sood AG, Sood A. Dental perspective on biomedical waste and mercury management: a knowledge, attitude and practice survey. Indian J Dent Res. 2011 May-Jun; 22(3):371-5. doi: 10.4103/0970-9290.87055.

9. Chudasama RK, Rangoonwala M, Sheth A, Misra SKC, Kadri MA, Patel UV. Biomedical Waste Management, A study of knowledge, attitude and practice among health care personnel at tertiary care hospital in Rajkot. Journal of Research in Medical and Dental Science 2013, 1(1), 17-22.

10. Charania ZK, Ingle NA. Awareness and practices of dental care waste management among dental practitioners in Chennai City. J Contemp Dent. 2011; 1:15-21. 
11. Sudhir KM. Awareness and practices about dental health care waste management among dentists of Davangere City, Karnataka. Journal of Indian Association of Public Health Dentistry 2006,8,44-50.

12. Mathur V, Dwivedi S, Hassan MA, Misra RP. Knowledge, attitude and practices about Bio-medical waste management among health care personnel: a cross-sectional study. Indian Journal of Community Medicine. 2011; 36: 143-145

13. Askarian M, Vakili M, Kabir G. Hospital waste management status in university hospitals of the Fars province, Iran. International Journal of Environmental Health Research 2004; 14 : 295-305.

14. Hassan MM, Ahmed SA, Rahman KA, Biswas TK. Pattern of medical waste management: existing scenario in Dhaka City, Bangladesh. BMC Public Health 2008; 36.

15. Kumar R, Samrongthong R, Shaikh BT. Knowledge, Attitude And Practices of health staff regarding infectious waste handling of tertiary care health facilities at metropolitan city of Pakistan. J Ayub Med Coll Abbottabad 2013; 25(1-2):109-12

16. Yadavannavar MC, Berad AS, Jagirdar PB. Biomedical Waste Management. A Study of Knowledge, Attitude, and Practices in a Tertiary Health Care Institution in Bijapur. Indian J Community Medicine 2010; I 35(1):170-1.

17. Rao PH. Hospital waste management-awareness and practices: A study of three states in India. Waste Manag Res 2008; 26:297-303.
18. Ndiaye M, El Metghari L, Soumah MM, Sow ML. Biomedical waste management in five hospitals in Dakar, Senegal. Bulletin de la Societé de pathologie exotique. 2012; 105: 296-304.

19. Shafee M, Kasturvar NB, Nirupama N. Knowledge, attitude an practices regarding biomedical waste among paramedical workers; Andrapradesh, Karimnagar, India. Indian J Community Med 2010; 35:369-70.

\section{Source of Support: Nil.}

Conflict of Interest: None Declared.

Copyright: (c) the author(s) and publisher. IJMRP is an official publication of Ibn Sina Academy of Medieval Medicine \& Sciences, registered in 2001 under Indian Trusts Act, 1882.

This is an open access article distributed under the terms of the Creative Commons Attribution Non-commercial License, which permits unrestricted non-commercial use, distribution, and reproduction in any medium, provided the original work is properly cited.

Cite this article as: Mohit Sharma, Mahima Sharma, Priyanka Kapoor, Suryakant Verma, Rekha Maheshwari, H. P. Gupta. Assessment of Knowledge, Attitude and Practice Regarding Biomedical Waste Management among Health Care Personnel in Jawahar Lal Nehru Medical College and Hospital, Ajmer (Rajasthan). Int J Med Res Prof. 2016; 2(4):155-58. 